\title{
Altura da lâmina, tempo e volume de enchimento de um equipamento de irrigação por pavio e determinação da uniformidade de distribuição de água em substratos
}

\author{
Rhuanito Soranz Ferrarezi (*); Leonardo Nazário Silva dos Santos; Allan Charles Mendes de Sousa; \\ Francisca Franciana Sousa Pereira; Marcelo Leite Conde Elaiuy; Uilson Torrel; Edson Eiji Matsura \\ Universidade Estadual de Campinas (UNICAMP), Faculdade de Engenharia Agrícola (FEAGRI), Conselho de Infraestrutura Rural, \\ Av. Cândido Rondon, 501, Cidade Universitária Zeferino Vaz, 13083-875 Campinas (SP), Brasil. \\ (*) Autor correspondente: rhuanito@terra.com.br
}

Recebido: 23/maio/2017; Aceito: 27/fev./2012

\begin{abstract}
Resumo
Os objetivos deste experimento foram realizar a avaliação da altura da lâmina de água, do tempo e volume de enchimento de um equipamento de irrigação por pavio usando calhas autocompensadoras e determinar a uniformidade de distribuição de água (UDA) nesse equipamento utilizando substratos orgânicos comerciais (casca de pinus/CP e fibra de coco/FC). Dois módulos experimentais foram montados em delineamento experimental inteiramente casualizado com cinco repetições. Verificou-se grande variação das medidas de altura da lâmina de água (1,6 a 4,0 cm), mesmo com o equipamento nivelado. O tempo médio de enchimento foi de 6h22min para o Módulo 1 com CP e de 3h45min para o Módulo 2 com FC. O volume de enchimento foi variável, observando-se que as calhas das extremidades (n. 1 e 5 ) apresentaram os menores volumes no Módulo 1, e as calhas do início ( $n$. $^{\circ}$ e 2) no Módulo 2. No Módulo 1, a umidade volumétrica ( $\Theta$ ) variou de 42\% a 94\%, e no Módulo 2, de 24\% a 72\%, com pontos isolados de secamento e/ou encharcamento. A altura da lâmina de água, o tempo e o volume de enchimento das calhas foram desuniformes nos dois módulos experimentais e nas cinco calhas autocompensadoras, indicando imperfeições no equipamento. A distribuição de água foi variável nos substratos em razão de suas características físico-hídricas e também da altura da lâmina de água nas calhas, apresentando maior umidade e uniformidade de distribuição de água na casca de pinus do que na fibra de coco.
\end{abstract}

Palavras-chave: capilaridade, casca de pinus, fibra de coco, subirrigação.

\section{Water depth, filling time and volume of wick irrigation equipment and determination of water distribution uniformity in substrates}

\footnotetext{
Abstract

The aims of this study were to evaluate the water depth, filling time and volume in a wick irrigation equipment using auto compensating gutters and to determine the water distribution uniformity (WDU) in these equipments filled with organic commercial substrates (pine bark/PB and coconut coir/CC). We assembled two experimental modules in a completely randomized design with five replications. There was variation in water depth measurements (1.6 to $4.0 \mathrm{~cm}$ ), even with the equipment leveled. Average filling time was 6h22min for Module 1 with PB and 3h45min for Module 2 with CC. The filling volume was variable, showing that gutters in the extremities (No. 1 and 5) had lower volumes in Module 1 and in the beginning (No. 1 and 2) in Module 2. Volumetric soil moisture $(\Theta)$ ranged from 42 to $94 \%$ in Module 1 and from 24 to $72 \%$ in Module 2, with isolated points of desiccation and/or flooding. Water depth, filling time and volume were disuniform in all experimental modules and auto compensating gutters, indicating equipment imperfections. Water distribution was variable in both substrates due to their hydro-physical characteristics and also water depth in the gutters, with higher humidity and water distribution uniformity in pine bark than in coconut coir.
}

Key words: capillarity, coconut coir, pine bark, subirrigation. 


\section{INTRODUÇÃO}

O cultivo em ambiente protegido vem se expandindo em função da necessidade de aumentar o controle sobre as condiçóes do ambiente para uniformizar a produção agrícola, reduzir a incidência de pragas e doenças e aumentar a qualidade e produtividade por área. No entanto, a maioria dos sistemas de irrigação utilizados em estufas possui baixa eficiência de aplicaçáo, o que gera custos elevados com bombeamento e implica na aplicação de quantidades excessivas de água com nutrientes e pesticidas, que não passam por tratamento para serem descartados, com potencial para contaminação do solo, lençóis freáticos e águas subterrâneas. Para minimizar esses impactos negativos ao meio ambiente, faz-se necessária a utilização de sistemas de irrigação poupadores de água, que proporcionem o reuso da solução nutritiva oriunda da drenagem, para tornar os cultivos ambiental e economicamente sustentáveis.

Uma alternativa seria o sistema de subirrigação usando pavio, baseado no princípio de capilaridade dos substratos, que se manifesta por meio da condução da água e nutrientes da base ao topo do recipiente de cultivo (Millar, 1988). As diferenças de gradiente do potencial total entre dois pontos no meio de cultivo levam à movimentação da água, que flui do local de maior para outro de menor potencial (CARON et al., 2005).

A subirrigação é indicada por Silva et al. (2005) como uma tecnologia adequada para aumentar a uniformidade de produção em ambiente protegido, permitindo o controle da quantidade de água fornecida em razão de ser um sistema fechado, sem geração de lixiviado para o ambiente. Além disso, possibilita redução na quantidade de água aplicada (James e Van IERSEL, 2001) e uma redução de $92,4 \%$ no tempo de funcionamento da motobomba (ANDRIOLO et al., 2004) em comparação com outros sistemas de irrigação, contribui para a redução da disseminação de patógenos (OH e Son, 2008), reduz a dispersão de contaminantes químicos durante a produçáo (Million et al., 1999) e proporciona fornecimento adequado dos nutrientes minerais (LAviola et al., 2007). Entretanto, apesar desses benefícios, a literatura indica que a principal limitação é a ocorrência de maior concentraçáo de sais nas camadas superiores do substrato (Richards e ReED, 2004).

Assim como ocorre em outros tipos de irrigação, o sistema de subirrigação necessita de equipamentos específicos para seu funcionamento usando o pavio. Atualmente existe somente um equipamento comercial disponível no mercado brasileiro, denominado calha autocompensadora, fabricado em polipropileno aditivado contra radiação ultravioleta e que funciona por gravidade, disponível em dois modelos: grande, para produção de hortaliças de frutos $(0,25 \mathrm{~m} \times 3,0 \mathrm{~m}$, capacidade para $42 \mathrm{~L}$ de substrato e reservatório inferior com $15 \mathrm{~L}$ ), e pequeno, para hortaliças folhosas $(0,18 \mathrm{~m}$ x 4,0 $\mathrm{m}$, capacidade para $26 \mathrm{~L}$ de substrato e reservatório inferior com $9 \mathrm{~L}$ ).

Um pavio de manta sintética não-tecida (MNT), conforme vantagens indicadas por SCATOLONI e Paterniani (2001), conduz água e/ou solução nutritiva de um reservatório inferior para o substrato localizado em um compartimento superior, umedecendo-o. É do substrato que a planta retira a água e os minerais de que necessita. Assim, à medida que a planta consome a solução nutritiva do substrato, o pavio, por diferença de potencial total de água, repóe a soluçáo automaticamente. É a própria planta que regula o fluxo de água em função da evapotranspiração, não havendo necessidade de bombeamento (Kinoshita e Masuda, 2011), sendo a taxa de absorção de água proporcional à largura do pavio (Kang et al., 2009).

No entanto, não existem avaliações hidráulicas nem informaçóes técnicas sobre o funcionamento desse equipamento de irrigação, o que dificulta seu dimensionamento e a recomendação de sua aplicação em escala comercial. Desta forma, os objetivos desse estudo foram: 1) avaliar a altura da lâmina de água, o tempo e o volume de enchimento de um equipamento de irrigação por pavio usando calhas autocompensadoras; 2) determinar a uniformidade de distribuição de água (UDA) nesse equipamento utilizando substratos orgânicos comerciais (casca de pinus/CP e fibra de coco/FC).

\section{MATERIAL E MÉTODOS}

O estudo foi realizado em estufa modelo Poly House situada em Campinas, SP (2249'11,86”S e 4703'40,56”O), de abril a junho de 2010. Foram utilizados equipamentos comerciais de irrigação por pavio denominados calhas autocompensadoras (Figura 1) para produção de hortaliças folhosas (tamanho pequeno), montados sobre pilares de madeira nivelados, seguindo as recomendaçóes técnicas do fabricante.

As calhas foram interligadas entre si por um microrreservatório, que possuía uma miniboia de altura ajustável que regulava o fluxo da água e/ou solução nutritiva proveniente do reservatório principal (Figura 2). Esta miniboia suportava uma altura manométrica de até 8 m.c.a.

Os módulos experimentais foram instalados em 2 conjuntos de 5 unidades cada uma, formados por reservatório principal, mangueira de borracha para adução de 3/4, microrreservatório intermediário com miniboia interna e cinco calhas autocompensadoras (Modelo pequeno; Hidrogood Horticultura Moderna, Taboão da Serra/SP), sendo cada calha considerada uma repetição. Ressalta-se que as calhas foram escolhidas aleatoriamente de um lote de fabricaçấo. Foram utilizados dois substratos orgânicos: casca de pinus/CP (Citros $9^{\circ}$; Mec Plant, Telêmaco Borba/PR) no Módulo 1 e fibra de coco/FC 
(Golden Mix Granulado ; Amafibra, Ananíndêua/PA) no Módulo 2. Cada bancada possuía 1,2 m de largura por 4,0 $\mathrm{m}$ de comprimento, eram niveladas e possuíam vazão variável em razão da miniboia do microrreservatório. Um módulo experimental completo pode ser observado na figura 3 .

Os ensaios foram realizados instalando-se o microrreservatório de acordo com as recomendaçôes do fabricante (seu nível inferior coincidiu com o nível inferior das calhas autocompensadoras). Como a altura da lâmina de água era controlada por uma miniboia que possuía diferentes regulagens, a altura do microrreservatório foi escolhida em função da determinação do volume máximo onde não ocorria drenagem de solução nutritiva pelo orifício de drenagem.

A altura da lâmina de água e o volume de enchimento das calhas vazias foram determinados em duas condiçóes: 1) no ponto de operação do sistema (até o microrreservatório parar de fornecer água às calhas) e 2) com água até o limite dos orifícios de drenagem (até ocorrer vazamento de água por um dos orifícios de drenagem). O tempo de enchimento das calhas foi determinado somente no ponto de operação do sistema. Foram realizadas três mediçôes para cada variável e usados os valores médios.

Em razão de os orifícios de drenagem possuírem alturas diferentes, ocasionando vazamentos, as determinaçóes foram finalizadas quando se notou, na primeira calha do Módulo, vazamento pelo orifício de drenagem nas duas condiçôes de coleta de dados.

A altura da lâmina de água no interior de cada calha foi determinada por meio da utilização de piezômetros instalados nas extremidades, inseridos na base do

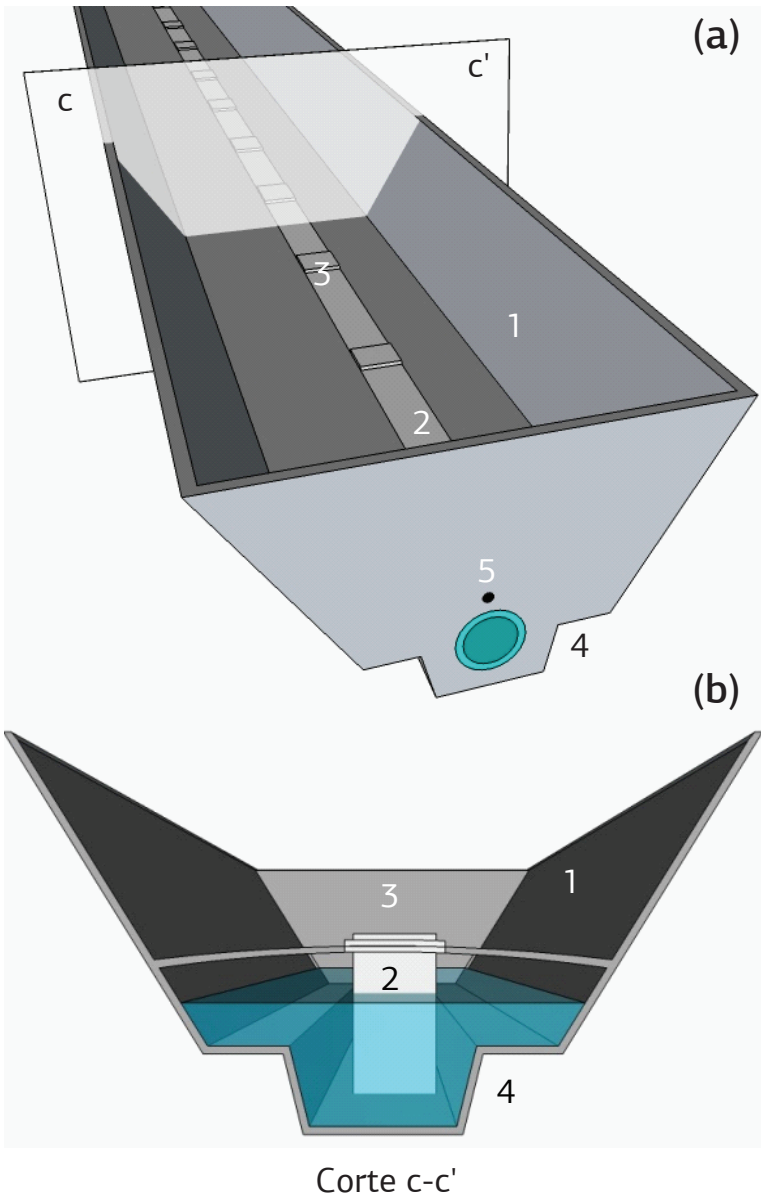

Figura 1. Calha autocompensadora, com (a) vista frontal e (b) corte transversal (corte c-c'). Onde: (1) compartimento para deposição do substrato, (2) manta sintética náo-tecida (MNT), (3) orifício de entrada da MNT no reservatório da calha a cada $0,40 \mathrm{~m},(4)$ reservatório inferior da calha e (5) orifício de drenagem.

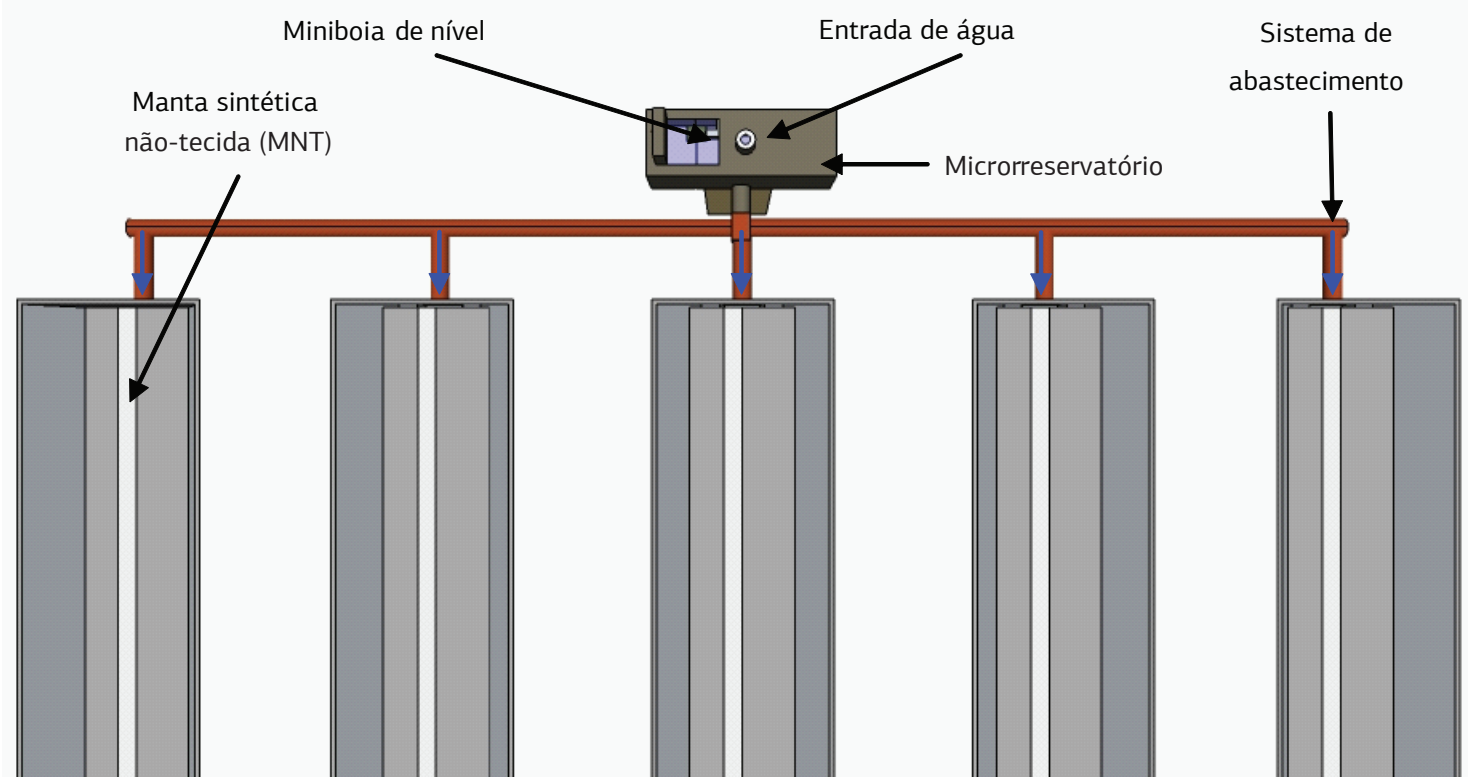

Figura 2. Detalhamento da estrutura de fornecimento de solução nutritiva nas calhas autocompensadoras dos módulos experimentais. Setas em azul indicam o sentido percorrido pela água. 


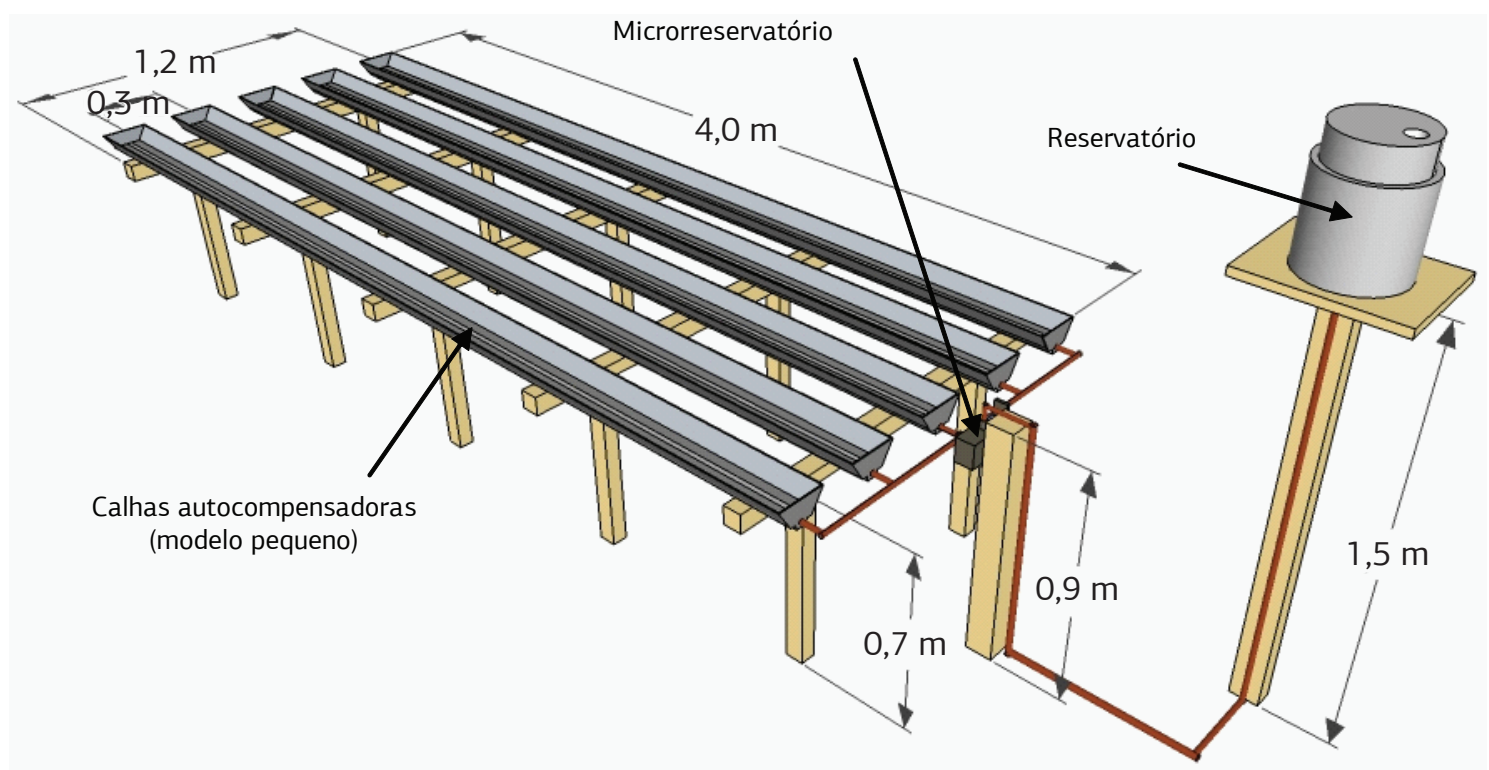

Figura 3. Módulo experimental, com as calhas autocompensadoras niveladas instaladas sobre bancadas de madeira, microrreservatório e reservatório.

reservatório da calha e colocados sobre réguas graduadas (adaptado de ANDriolo et al., 2004).

Para avaliar a lâmina ao longo de toda a calha, foram inseridos palitos de madeira a cada $0,40 \mathrm{~m}$ nos orifícios de entrada da MNT no reservatório da calha, totalizando 11 pontos de coleta, nos quais se realizou marcação da altura do nível de água e mensuração dessa altura com uma régua graduada. Essa operação foi realizada uma única vez e permitiu observar possíveis irregularidades do reservatório interno das calhas.

O tempo de enchimento das calhas foi controlado por um cronômetro digital, acionado manualmente no momento de início de fornecimento de água e desligado quando o sistema se estabilizou, observado pela ausência de entrada de água pela miniboia do microrreservatório. Como o sistema não era pressurizado, a vazão era livre e ocasionava diferenças nas leituras do tempo de enchimento das calhas. Desta forma, realizaram-se seis avaliaçóes preliminares para padronização das leituras.

$\mathrm{O}$ volume de água de cada calha autocompensadora foi obtido utilizando-se proveta com capacidade de $1000 \mathrm{~mL}$.

Para elaboração dos mapas de uniformidade de distribuição de água (UDA), as calhas foram preenchidas com substratos orgânicos (CP no Módulo 1 e FC no Módulo 2) e irrigadas manualmente até a saturação para elevaçáo da condutividade hidráulica, responsável pela redistribuição de água nos meios de cultivo (Burgess, 2011). Após três dias, os substratos foram amostrados em ziguezague a cada $10 \mathrm{~cm}$ da superfície até a base da canaleta, em um total de 41 pontos de amostragem ao longo da calha. A umidade do substrato foi determinada pelo método gravimétrico, realizando-se também determinaçáo da densidade e da porosidade total para cálculo da umidade volumétrica $(\Theta)$ (EMBRAPA, 1997). Os valores médios da densidade do substrato usados no cálculo da umidade volumétrica foram $0,092 \mathrm{~g} \mathrm{~cm}^{-3}$ para a CP e $0,375 \mathrm{~g} \mathrm{~cm}^{-3}$ para a FC. A porosidade total foi de $59,9 \%$ para a CP e $82,8 \%$ para a FC.

Os resultados da altura da lâmina, do tempo e do volume de enchimento das calhas no ponto de operação do sistema e com água até o limite dos orifícios de drenagem foram submetidos à análise de variância utilizando-se o software estatístico R 2.14.1 (R Development Core Team, 2012) e as médias comparadas usando o teste de Tukey a 5\%. Os resultados da UDA foram submetidos ao método de interpolação por krigagem no software Surfer 9.0 para confecção dos mapas de umidade do substrato.

\section{RESULTADOS E DISCUSSÃO}

\section{Altura da lâmina, tempo e volume de enchimento do sistema no ponto de operação}

Verificou-se que houve diferenças entre os módulos experimentais quanto ao tempo de enchimento das calhas do sistema no ponto de operaçáo. O tempo médio de enchimento foi de 6h22min para o Módulo 1 e de $3 \mathrm{~h} 45 \mathrm{~min}$ para o Módulo 2. Essa diferença ocorreu porque a vazão do sistema foi afetada pela desuniformidade interna das calhas, demonstrado pelas diferentes alturas da lâmina de água indicadas a seguir.

A altura da lâmina de água obtida pela leitura de piezômetros e o volume de água para enchimento das calhas 
nos Módulos 1 e 2 podem ser observados na tabela 1 . Observou-se grande variaçáo nas medidas obtidas, principalmente entre o piezômetro inicial e final, que pode ser decorrente de ondulaçôes internas provenientes do processo de fabricação do equipamento, ou por sua deformação em razão de altas temperaturas no interior da estufa. Estes fatores ocasionaram irregularidades no perfil da calha ao longo do seu comprimento, mesmo instaladas sobre pilares nivelados, interferindo nas leituras realizadas. Desta forma, a lâmina de água manteve-se irregular mesmo seguindo as recomendações técnicas de instalação do equipamento. Com relaçâo ao volume, verificaram-se diferenças entre as calhas e entre os módulos: as calhas das extremidades (n. ${ }^{\circ} 1$ e 5 ) no Módulo 1 e as calhas n. ${ }^{\circ} 1$ e 2 do Módulo 2 apresentaram os menores volumes de água para enchimento (Tabela 1).
$\mathrm{Na}$ figura 4, pode-se observar os níveis de água no reservatório de cada calha, que foram medidos nos orifícios de entrada da MNT, para cada Módulo experimental. Observou-se grande variação entre as calhas, com diferenças dentro e entre os módulos nos níveis de água, com variaçóes maiores que 50\% no Módulo 1 e maiores que $100 \%$ no Módulo 2. Essa variação indica que o equipamento fornece quantidades diferentes de água em cada orifício de entrada da MNT, o que pode afetar a uniformidade de distribuiçáo de água, alterar o desenvolvimento das plantas e, consequentemente, a uniformidade de produção.

No entanto, as análises mostraram que não houve diferença estatística $(\mathrm{p}>0,05)$ na altura média de água no ponto de operação do sistema no Módulo 1 (Tabela 2). Porém, observou-se diferença no Módulo 2 ( $\mathrm{p}<0,05)$,

Tabela 1. Altura da lâmina de água nos piezômetros (ALAP) instalados no início e final de cada calha, volume de água por calha e volume total nos Módulos 1 e 2, com o sistema no ponto de operação. Média de três repetições

\begin{tabular}{|c|c|c|c|c|c|c|c|c|c|c|}
\hline \multirow{2}{*}{ Variáveis } & \multicolumn{5}{|c|}{ Calhas no Módulo 1} & \multicolumn{5}{|c|}{ Calhas no Módulo 2} \\
\hline & 1 & 2 & 3 & 4 & 5 & 1 & 2 & 3 & 4 & 5 \\
\hline ALAP no início (cm) & 3,5 & 2,9 & 3,0 & 2,9 & 2,9 & 2,1 & 2,2 & 2,3 & 2,1 & 2,2 \\
\hline Volume de água (L) & 4,7 & 5,8 & 5,9 & 5,1 & 3,7 & 2,1 & 3,8 & 5,1 & 5,1 & 4,2 \\
\hline Volume total de água (L) & & & 25,3 & & & & & 20,3 & & \\
\hline
\end{tabular}

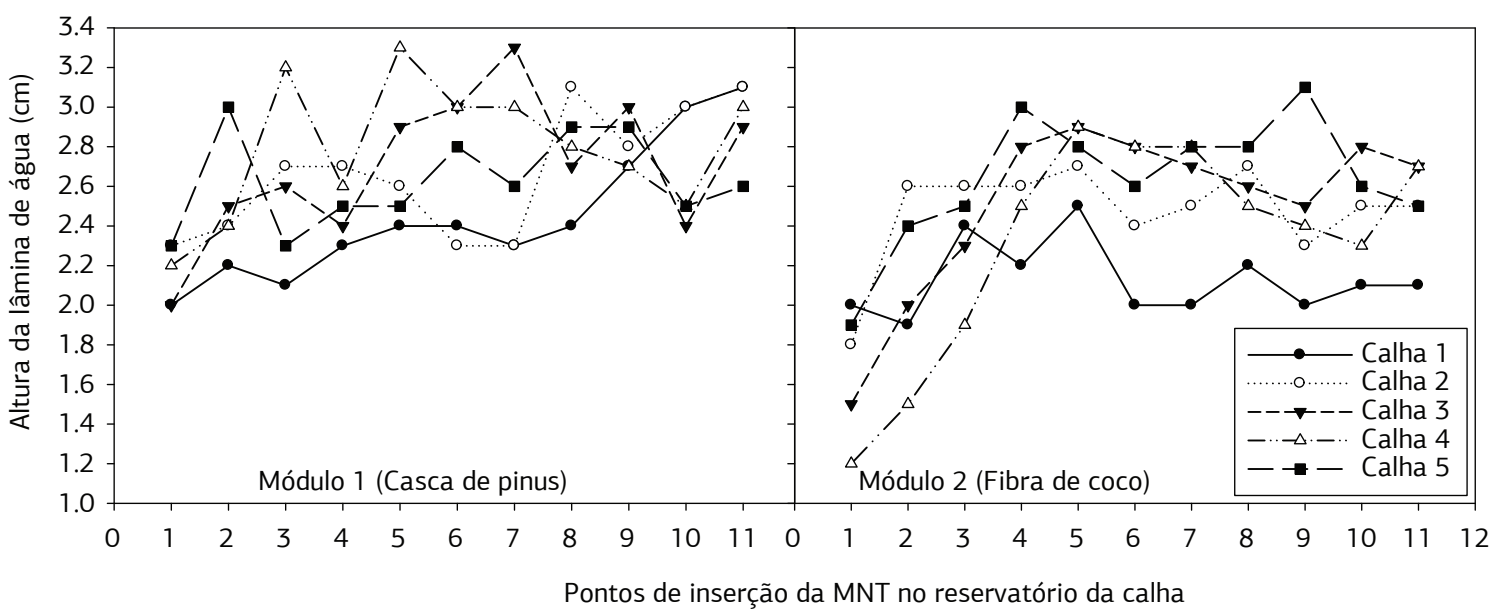

Figura 4. Altura da lâmina de água nos pontos de inserção da manta sintética não-tecida (MNT) nos Módulos 1 e 2, com o sistema no ponto de operação.

Tabela 2. Análise estatística descritiva da altura da lâmina de água nos pontos de inserção da manta sintética não-tecida (MNT) nos Módulos 1 e 2, com o sistema no ponto de operação

\begin{tabular}{|c|c|c|c|c|c|c|c|c|c|c|}
\hline \multirow{2}{*}{ Estatística descritiva } & \multicolumn{5}{|c|}{ Calhas no Módulo 1} & \multicolumn{5}{|c|}{ Calhas no Módulo 2} \\
\hline & 1 & 2 & 3 & 4 & 5 & 1 & 2 & 3 & 4 & 5 \\
\hline Média $(\mathrm{cm})$ & 2,4 ns & $2,7^{\mathrm{ns}}$ & $2,7^{\mathrm{ns}}$ & 2,8 ns & 2,6 ns & $2,1 \mathrm{~b}$ & $2,5 a b$ & $2,5 \mathrm{a}$ & $2,3 a b$ & $2,6 \mathrm{a}$ \\
\hline Desvio-padrão (cm) & 0,4 & 0,3 & 0,4 & 0,3 & 0,2 & 0,2 & 0,3 & 0,4 & 0,6 & 0,3 \\
\hline Máximo $(\mathrm{cm})$ & 3,1 & 3,1 & 3,3 & 3,3 & 3,0 & 2,5 & 2,7 & 2,9 & 2,9 & 3,1 \\
\hline Mínimo (cm) & 2,0 & 2,3 & 2,0 & 2,2 & 2,3 & 1,9 & 1,8 & 1,5 & 1,2 & 1,9 \\
\hline CV (\%) & 14,3 & 11,8 & 13,6 & 12,4 & 9,2 & 8,7 & 10,2 & 17,0 & 24,1 & 12,4 \\
\hline
\end{tabular}

Médias seguidas das letras ${ }^{n s}$ indicam ausência de significância; médias seguidas da mesma letra minúscula na linha nâo diferem entre si em nível de $5 \%$ de probabilidade no teste de Tukey. 
com o menor valor para a calha $n .^{\circ} 1$ e maior para as calhas n. 3 e 5 (Tabela 2). Pelos resultados, verifica-se que existem ondulaçóes internas ao longo de toda calha, o que está em concordância com os resultados das lâminas iniciais e finais apresentados na tabela 1 .

\section{Altura da lâmina e volume de enchimento do sistema até o orifício de drenagem}

Realizou-se também a medição da altura da lâmina e do volume de enchimento do sistema até o orifício de drenagem das calhas, sendo os resultados listados na tabela 3. Constatou-se que a furação dos orifícios de drenagem não era padronizada, havendo variação das lâminas de água e, consequentemente, dos volumes de enchimento. O funcionamento do equipamento nessas condiçóes ocasionaria vazamentos pelo orifício de drenagem antes de a água estar uniformemente distribuída no sistema, gerando problemas na sua operação, já que algumas calhas não estariam completamente cheias. Isso acabaria prejudicando a uniformidade de distribuição de água e, acima de tudo, gerando perda de água e nutrientes.

Mediu-se também a altura de água no nível máximo dos orifícios de drenagem nos locais de entrada da MNT nos Módulos 1 e 2 (Figura 5). Observa-se nessa figura que as calhas n. ${ }^{\circ} 1$ e 2 do Módulo 1 tinham lâminas muito inferiores às demais, e que na calha n. ${ }^{\circ} 5$ do Módulo 2 a lâmina era maior do que as outras calhas autocompensadoras.

Observou-se diferença significativa $(\mathrm{p}<0,01)$ na altura de água dos dois módulos experimentais (Tabela 4), com destaque para os baixos valores observados na calha 1 do primeiro Módulo e nas calhas n. ${ }^{\circ} 1,3$ e 4 do segundo

Tabela 3. Altura da lâmina de água nos piezômetros (ALAP) instalados no início e final de cada calha e volume de água por calha e total nos Módulos 1 e 2, com o sistema até o orifício de drenagem. Média de três repetiçóes

\begin{tabular}{|c|c|c|c|c|c|c|c|c|c|c|}
\hline \multirow{2}{*}{ Variáveis } & \multicolumn{5}{|c|}{ Calhas no Módulo 1} & \multicolumn{5}{|c|}{ Calhas no Módulo 2} \\
\hline & 1 & 2 & 3 & 4 & 5 & 1 & 2 & 3 & 4 & 5 \\
\hline ALAP no início (cm) & 1,6 & 2,6 & 2,4 & 2,5 & 2,6 & 3,5 & 4,0 & 3,9 & 3,8 & 3,9 \\
\hline Volume de água (L) & 4,0 & 5,2 & 7,1 & 8,2 & 6,7 & 4,1 & 8,6 & 6,0 & 5,5 & 10,4 \\
\hline Volume total de água (L) & & & 31,2 & & & & & 34,6 & & \\
\hline
\end{tabular}

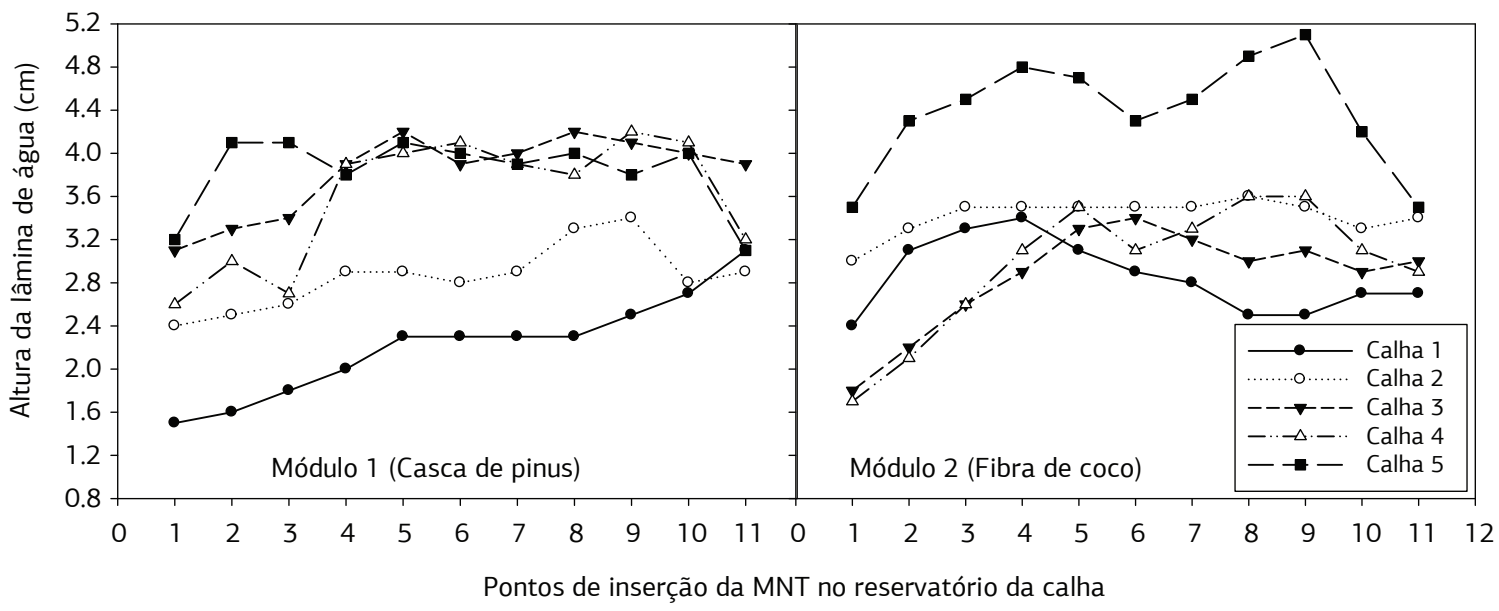

Figura 5. Altura da lâmina de água nos pontos de inserção da manta sintética não-tecida (MNT) nos Módulos 1 e 2, com o sistema até o nível máximo do orifício de drenagem.

Tabela 4. Análise estatística da altura da lâmina de água nos pontos de inserção da manta sintética não-tecida (MNT) nos Módulos 1 e 2 , com o sistema até o nível máximo do orifício de drenagem

\begin{tabular}{|c|c|c|c|c|c|c|c|c|c|c|}
\hline \multirow{2}{*}{ Estatística descritiva } & \multicolumn{5}{|c|}{ Calhas no Módulo 1} & \multicolumn{5}{|c|}{ Calhas no Módulo 2} \\
\hline & 1 & 2 & 3 & 4 & 5 & 1 & 2 & 3 & 4 & 5 \\
\hline Média (cm) & $2,2 \mathrm{c}$ & $2,9 \mathrm{~b}$ & $3,8 \mathrm{a}$ & $3,6 \mathrm{a}$ & $3,8 \mathrm{a}$ & $2,9 \mathrm{c}$ & $3,4 \mathrm{~b}$ & $2,9 \mathrm{c}$ & $3,0 \mathrm{bc}$ & $4,4 \mathrm{a}$ \\
\hline Desvio-padrão (cm) & 0,5 & 0,3 & 0,4 & 0,6 & 0,4 & 0,3 & 0,2 & 0,5 & 0,6 & 0,5 \\
\hline Máximo $(\mathrm{cm})$ & 3,1 & 3,4 & 4,2 & 4,2 & 4,1 & 3,4 & 3,6 & 3,4 & 3,6 & 5,1 \\
\hline Mínimo (cm) & 1,5 & 2,4 & 3,1 & 2,6 & 3,1 & 2,4 & 3,0 & 1,8 & 1,7 & 3,5 \\
\hline CV (\%) & 21,3 & 10,6 & 9,9 & 16,6 & 9,2 & 11,8 & 4,9 & 16,9 & 20,7 & 11,8 \\
\hline
\end{tabular}

Médias seguidas da mesma letra minúscula na linha nâo diferem entre si em nível de $1 \%$ de probabilidade no teste de Tukey. 
Módulo. De maneira semelhante ao encontrado no ponto de operação do sistema, houve desuniformidade ao longo de toda a calha, o que foi coerente com os valores das lâminas iniciais e finais da tabela 3 .

Porém, SiLva et al. (2005) observaram que sistemas de irrigação capilares apresentaram produção de matéria fresca da parte aérea superior ao sistema de hidroponia, indicando que embora existam diferenças ao longo do equipamento, o substrato uniformiza a distribuição de água, com resposta positiva na produção, sugerindo que o cultivo hidropônico pudesse ser substituído por sistemas que utilizam pavio.

\section{Uniformidade de distribuição de água (UDA) nos substratos}

Diferente do esperado, a desuniformidade na altura da lâmina, no tempo e no volume de enchimento não reduziu a UDA nas calhas com substratos (Módulo 1 preenchido com CP e Módulo 2 com FC), havendo distribuição uniforme da umidade ao longo da calha, com alguns pontos isolados de secamento e/ou encharcamento. Esse processo está de acordo com KANG et al. (2009), que comprovaram que a taxa de absorção de água pelo substrato é dependente da largura do pavio, e que a umidade aumenta com o passar do tempo, principalmente nas primeiras 24 horas, estabilizando-se posteriormente. Resultados semelhantes foram avaliados por Son et al. (2002), porém com tempo de estabilização de 5 horas. OH et al. (2007) notaram que um tempo de 40 a 60 minutos foi necessário para que pavios de 2 e $3 \mathrm{~cm}$ de largura, respectivamente, aumentassem o conteúdo volumétrico de água do substrato de $18 \%$ para $30 \%$. Million et al. (2007) observou que o pavio mantém uma umidade constante no substrato, sendo o movimento da água diretamente relacionado às perdas por evapotranspiraçáo.

No Módulo 1, a UDA variou de $42 \%$ a $94 \%$ no substrato à base de CP (Figura 6). No entanto, observa-se que houve maior frequência de valores $(>80 \%)$ de umidade entre $52 \%$ e $64 \%$ nas cinco calhas. Esses valores são superiores aos encontrados por Son et al. (2006) (de 22\% a $38 \%$ ), por $\mathrm{OH}$ e Son (2008) (de $20 \%$ a $30 \%$ ) e por Grant et al. (2009) (de 10\% a 25\%), cujos sistemas e substratos utilizados eram diferentes.
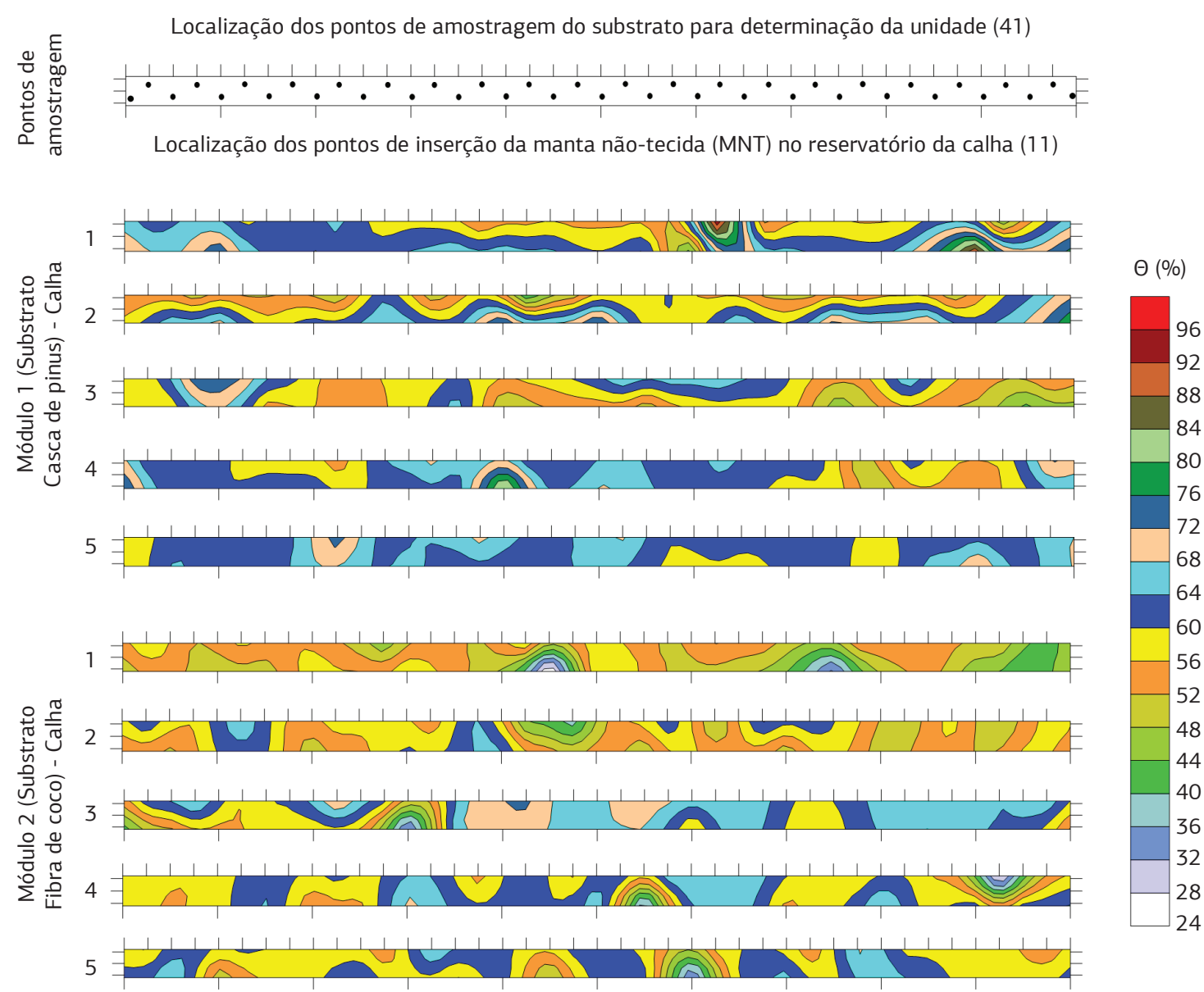

Figura 6. Uniformidade de distribuição de água no substrato, expressa em umidade volumétrica $(\Theta, \%)$, de calhas preenchidas com casca de pinus no Módulo 1 e fibra de coco no Módulo 2. 
Segundo ZanetTi et al. (2003), partículas com maior diâmetro são responsáveis pela formação de poros maiores (macroporos), que são ocupados por ar; por outro lado, partículas de menor diâmetro são responsáveis pela formação de poros menores (microporos), que são ocupados por água. A umidade volumétrica do substrato é elevada para um substrato com menor tamanho de partículas, com potencial para ocorrência de elevadas perdas por evaporação quando expostas a elevadas temperaturas, fato observado na $\mathrm{CP}$, visto que este substrato apresentou menor porosidade total em relação à da FC $(59,9 \%$ e $82,8 \%$ respectivamente). Essa característica pode ocasionar salinizaçáo do substrato, uma vez que a evaporação é maior e há possibilidade de ocorrer concentração de sais (Richards e ReED, 2004).

Portanto, a escolha do substrato é fundamental para melhorar a uniformidade de distribuição de água, uma vez que os diferentes componentes afetam a capacidade do meio em promover ascensáo capilar de água e nutrientes, mesmo quando o sistema apresenta imperfeiçóes decorrentes do seu processo de fabricação. Ressalta-se que outros substratos podem ser utilizados, em razão das características físicas que se deseja obter para produção (Milner, 2002).

A UDA no Módulo 2 (substrato de FC) pode ser observada na figura 6 . A $\Theta$ variou de $24 \%$ a $72 \%$, com maior frequência de valores (>80\%) entre $44 \%$ e $64 \%$ nas cinco calhas. Da mesma maneira que no Módulo 1 , esses resultados foram abaixo dos valores observados por Son et al. (2006), que variaram de $22 \%$ a $38 \%$ em um sistema de pavio com fluxo constante de solução nutritiva, de maior velocidade e baixo contato da lâmina de irrigaçáo com o substrato do que o sistema testado nesse experimento.

A FC apresentou visualmente maior retenção de água quando comparada à $\mathrm{CP}$, o que pode ser explicado pelas

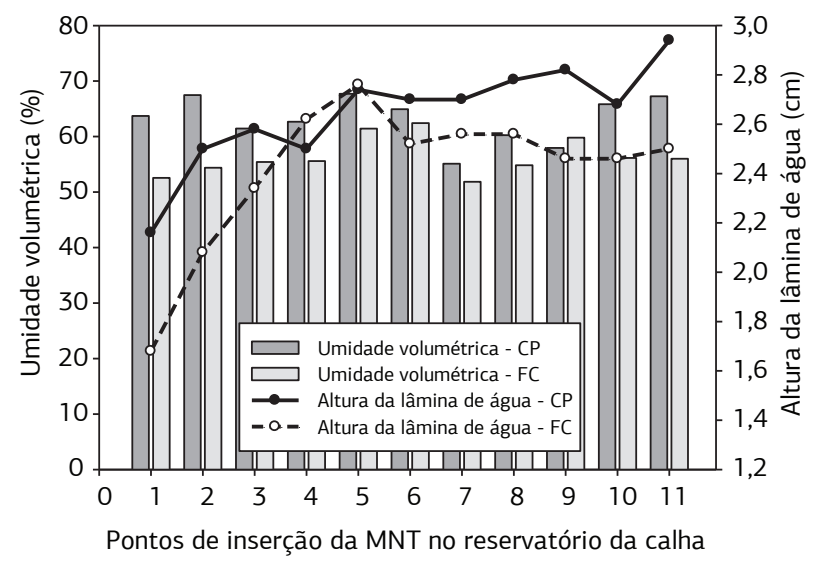

Figura 7. Médias de umidade volumétrica $(\Theta)$ e altura da lâmina de água nos pontos de inserção da manta sintética não-tecida (MNT) nos Módulos 1 (casca de pinus, CP) e 2 (fibra de coco, FC), obtidas na determinação da uniformidade de distribuição de água dos substratos. características físicas favoráveis à retenção de água que a FC apresenta no interior de suas partículas (Fermino, 2002). Essa retenção promove o preenchimento dos poros deste substrato com maior quantidade de água, podendo levar o produtor a sub ou superestimar a irrigação se não realizar a medição da umidade nos substratos, especificamente aqueles com FC na sua composição.

Os resultados da avaliação da altura da lâmina, do tempo e do volume de enchimento foram relacionados com a determinação da UDA nos substratos na figura 7 , observando-se a $\Theta$ e a altura de água nos pontos de inserção da MNT no reservatório das calhas. No Módulo 1 a umidade média mínima foi de $55,1 \%$ no ponto 7 e acima de $67 \%$ nos pontos 2,5 e 11 , indicando variação significativa da umidade em relação aos pontos de inserçấo da MNT (Figura 7). No Módulo 2, a umidade média mínima foi de $51,9 \%$ no ponto 7 , ficando com $62,4 \%$ no ponto 6 (Figura 7). Variaçōes na altura da lâmina de água nas calhas com $\mathrm{CP}$ em geral corresponderam a aumentos na umidade do substrato, porém nas calhas com FC não houve relação direta, pois observou-se que a umidade não variou com os aumentos na altura da lâmina nos pontos $1 \mathrm{a} 4$ de inserção da MNT.

\section{Recomendações finais}

Melhorias no processo de fabricação do equipamento e na qualidade da matéria-prima são necessárias para corrigir ondulaçóes do reservatório interno das calhas e prevenir deformaçóes dentro de ambientes protegidos. $\mathrm{O}$ equipamento deve estar perfeitamente nivelado para correto funcionamento, e a altura do orifício de drenagem deve ser padronizada para evitar vazamentos antes da estabilizaçáo do sistema e impedir o pleno enchimento de todas as calhas. $\mathrm{O}$ equipamento tem potencial para utilização em situaçôes onde a energia elétrica é limitada. Estudos futuros são necessários para estabelecer o manejo hídrico e nutricional no sistema de pavio para plantas de interesse comercial.

\section{CONCLUSÃO}

A altura da lâmina de água, o tempo e o volume de enchimento das calhas foram desuniformes nos dois módulos experimentais e nas cinco calhas autocompensadoras, tanto no ponto de operação do sistema quanto no sistema cheio até o orifício de drenagem, indicando imperfeiçôes no equipamento.

A distribuição de água foi variável nos substratos em razão de suas características físico-hídricas e também da altura da lâmina de água nas calhas, com maior umidade e uniformidade de distribuição de água na casca de pinus do que na fibra de coco. 


\section{AGRADECIMENTOS}

Ao Grupo de Pesquisa Tecnologia de Irrigação e Meio Ambiente, ao Técnico de Laboratório Gelson Espíndola, ao acadêmico Antonio Carlos Ferreira Filho, à Diretoria da FEAGRI/UNICAMP, à Hidrogood Horticultura Moderna e ao CNPq.

\section{REFERÊNCIAS}

ANDRIOLO, J.L.; LUZ, G.L.; GIRALDI, C.; GODOI, R.S.; BARROS, G.T. Cultivo hidropônico da alface empregando substratos: uma alternativa a NFT? Horticultura Brasileira, v.22, p.794-798, 2004.

BURGESS, S.S.O. Can hydraulic redistribution put Bread on our table? Plant and Soil, v.341, p.25-29, 2011.

CARON, J.; ELRICK, D.E.; BEESON, R.; BOUDREAU, J. Defining critical capillary rise properties for growing media in nurseries. Soil Science Society American Journal, v.69, p.794-806, 2005.

EMBRAPA - Empresa Brasileira de Pesquisa Agropecuária. Manual de métodos de análises de solo. Rio de Janeiro: Centro Nacional de Pesquisa de Solos, 1997. p.15-21.

FERMINO, M.H. Uso da análise física na avaliação da qualidade de componentes e substratos. In: FURLANI, A.M.; BATAGLIA, O.C.; ABREU, M.F.; ABREU, C.A.; FURLANI, P.; QUAGGIO, J.A. Caracterização, manejo e qualidade de substratos para produção de plantas. Campinas: IAC, 2002 p.4552. (Documentos IAC, 70)

GRANT, O.M.; DAVIES, M.J.; LONGBOTTOM, H.; ATKINSON, C.J. Irrigation scheduling and irrigation systems: optimizing irrigation efficiency for container ornamental shrubs. Irrigation Science, v.27, p.139-153, 2009.

JAMES, E.; VAN IERSEL, M.W. Ebb and flow production of petunias and begonias as affected by fertilizers with different phosphorus content. HortScience, v.36, p.282-285, 2001.

KANG, S.W.; SEO, S.G.; PAK, C.H. Capillary wick width and water level in channel affects water absorption properties of growing media and growth of chrysanthemum and poinsettia cultured in c-channel subirrigation system. Korean Journal of Horticultural Science \& Technology, v.27, p.86-92, 2009.

KINOSHITA, T.; MASUDA, M. Differential nutrient uptake and its transport in tomato plants on different fertilizer regimens. HortScience, v.46, p.1170-1175, 2011.

LAVIOLA, B.G.; MARTINEZ, H.E.; MAURI, A.L. Influência do nível de adubação de plantas matrize $s$ na formação de mudas de cafeeiros em sistema hidropônico. Ciência e Agrotecnologia, v.31, p.1043-1047, 2007.
MILLAR, A.A. Drenagem de terras agrícolas: bases agronômicas. São Paulo: Editerra, 1988. p.17-28.

MILLION, J.; YEAGER, T.; LARSEN, C. Water use and fertilizer response of azalea using several no-leach irrigation methods. HortTechnology, v.17, p.21-25, 2007.

MILLION, J.B.; BARRETT, J.E.; NELL, T.A.; CLARK, D.G. Inhibiting growth of flowering crops with Ancymidol and Paclobutrazol in subirrigation water. HortScience, v.34, p.1103$1105,1999$.

MILNER, J. Manejo da irrigação e fertirrigação em substratos. In: FURLANI, A.M.C.; BATAGLIA, O.C.; ABREU, M.F.; ABREU, C.A.; FURLANI, P.R.; QUAGGIO, J.A. Caracterização, manejo e qualidade de substratos para produçáo de plantas. Campinas: IAC, 2002. p.45-52. (Documentos IAC, 70 )

OH, M.M.; CHO, Y.Y.; KIM, K.S.; SON, J.E. Comparison of water content of growing media and growth of potted kalanchoe among nutrient-flow wick culture and other irrigation systems. HortTechnology, v.17, p.62-66, 2007.

$\mathrm{OH}$, M.; SON, J.E. Phytophthora nicotianae transmission and growth of potted kalanchoe in two recirculating subirrigation systems. Scientia Horticulturae, v.119, p.75-78, 2008.

R DEVELOPMENT CORE TEAM. R: A Language and environment for statistical computing. Vienna, Austria: R Foundation for Statistical Computing, 2012. Disponível: http:// www.r-project.org. Acesso em 28/2/2012.

RICHARDS, D.L.; REED, D.W. New Guinea Impatiens growth response and nutrient release from controlled-release fertilizer in a recirculating subirrigation and top-watering system. HortScience, v.39, p.280-286, 2004.

SCATOLONI, M.E.; PATERNIANI, J.E.S. Remoção dos sólidos suspensos na água de irrigação utilizando mantas sintéticas não tecidas. Revista Brasileira de Engenharia Agrícola e Ambiental, v.5, p.382-385, 2001.

SILVA, J.O.; SOUZA, P.A.; GOMES JÚNIOR, J.; PEREIRA, P.R.; ROCHA, F.A. Crescimento e composição mineral da alface no sistema hidropônico por capilaridade. Irriga, v.10, p.146-154, 2005.

SON, J.E.; JUNG, D.H.; LUI, Y.J. Analysis of root zone environment in pot plant production system with subirrigation method using wick. Acta Horticulture, n.578, p.389-393, 2002

SON, J.E.; OH, M.M.; LU, Y.J.; KIM K.S.; GIACOMELLI, G.A. Nutrient-flow wick culture system for potted plant production: system characteristics and plant growth. Scientia Horticulturae, v.107, p.392-398, 2006.

ZANETTI, M.; FERNANDES, C.; CAZETTA, J.O.; CORÁ, J.E.; MATTOS JUNIOR, D. Características físicas de substratos para a produção de mudas cítricas sob telado. Laranja, v.24, p.519530, 2003. 